\title{
Expression of cellular fibronectin mRNA in adult periodontitis and peri-implantitis: a real-time polymerase chain reaction study
}

\begin{abstract}
Yan-Yun Wu, Huan-Huan Cao, Ning Kang, Ping Gong and Guo-Min Ou
Cellular fibronectin ( $\mathrm{CFn}$ ) is a type of bioactive non-collagen glycoprotein regarded as the main substance used to maintain periodontal attachment. The content of $\mathrm{cFn}$ in some specific sites can reflect the progress of periodontitis or peri-implantitis. This study aims to evaluate the expression of $\mathrm{cFn}$ messenger RNA (mRNA) in tissues of adult periodontitis and peri-implantitis by real-time fluorescent quantitative polymerase chain reaction (PCR) and to determine its clinical significance. A total of 30 patients were divided into three groups of 10: healthy, adult periodontitis and peri-implantitis. Periodontal tissue biopsies $(1 \mathrm{~mm} \times 1 \mathrm{~mm} \times 1 \mathrm{~mm})$ from each patient were frozen in liquid nitrogen. Total RNA was extracted from these tissues, and the content, purity and integrity were detected. Specific primers were designed according to the sequence, and the mRNA expression levels of cellular fibronectin were detected by real-time PCR. The purity and integrity of the extracted total RNA were both high, and the specificity of amplified genes was very high with no other pollution. The mRNA expression of $\mathrm{CFn}$ in the adult periodontitis group $(1.526 \pm 0.441)$ was lower than that in the healthy group $(3.253 \pm 0.736)$. However, the mRNA expression of $\mathrm{cFn}$ in the peri-implantitis group $(3.965 \pm 0.537)$ was significantly higher than that in the healthy group. The difference revealed that although both processes were destructive inflammatory reactions in the periodontium, the pathomechanisms were different and the variation started from the transcription level of the $c F n$ gene. International Journal of Oral Science (2013) 5, 212-216; doi:10.1038/ijos.2013.65; published online 6 September 2013
\end{abstract}

Keywords: adult periodontitis; cellular fibronectin; peri-implantitis; real-time polymerase chain reaction

\section{INTRODUCTION}

Cellular fibronectin (cFn) is a type of non-collagen glycoprotein with an important bioactivity that exists abundantly in the periodontium. Functioning as a substance that maintains the periodontal attachment, cFn takes part in many physiological processes such as cellular adhesion, proliferation and differentiation; restoration and regularization of the epithelium array; and immune regulation. In adult periodontitis, the increment of degraded cFn segments was demonstrated as the result of periodontal tissue inflammation and destruction. ${ }^{1}$

Oral implantation is a breakthrough in the development of dentistry and provides a better choice to restore missing teeth. However, the cause of bone loss and failure of implantation in peri-implantitis needs to be explored. The content of cFn in periodontal tissue may be related to the state of implants because it is a vital component of the extracellular matrix. ${ }^{2}$

So far, studies on the expression of cFn in the periodontium are not sufficient. Experiments at the protein level have been performed through immunohistochemistry, ${ }^{3}$ and the expression of cFn messenger RNA (mRNA) in the periodontium has been examined using reverse transcription polymerase chain reaction (PCR). ${ }^{4}$ However, the immunohistochemistry test is merely qualitative, has high subjectivity, and sometimes results in certain false positive and negative rates. Reverse transcription PCR could be used to detect minute mRNA, but its doubtful accuracy and tedious steps may not result in a convincing outcome.

Real-time fluorescent quantitative PCR could precisely solve the above problems. By adding fluorescent radical in the reaction system, the whole amplificative process could be monitored through the cumulative fluorescent signal. After working out the standard curve and obtaining the cycle threshold $\left(C_{\mathrm{t}}\right)$ value of one sample, the content of the amplified gene could be directly measured through the curve.

This study aims to observe the expression discrepancy of cFn mRNA in patients with periodontitis and peri-implantitis at the transcriptional level by real-time PCR, and discuss the relation between $\mathrm{CFn}$ and the development of these diseases.

\section{MATERIAL AND METHODS}

Subjects and sample collection

A total of 30 subjects referred to the Out-patient Department of West China Hospital of Stomatology, Sichuan University were divided into three groups of 10: periodontitis, peri-implantitis and healthy control. Inflamed gingival tissues (approximately $1 \mathrm{~mm} \times 1 \mathrm{~mm} \times 1 \mathrm{~mm}$ ) were collected from the active periodontal inflammation site of 10 chronic periodontitis subjects (five males and five females aged 20-60 years 
with an average age of 45.0 years) under the following inclusion criteria: gingival index $>1$, at least five sites with probing depth $\geqslant 4 \mathrm{~mm}$, clinical attachment loss $\geqslant 1-2 \mathrm{~mm}$ and extensive radiographic bone loss $\geqslant 1 / 3$ of the root length in the surgery quadrant while sampling. Gingival tissues (approximately $1 \mathrm{~mm} \times 1 \mathrm{~mm} \times 1 \mathrm{~mm}$ ) of the periimplantitis patients were collected from the obvious inflammation site in 10 subjects (five males and five females aged 20-60 years with an average age of 47.4 years) under the following inclusion criteria: pain and swelling signs in gingiva with/without presence of pus, movable parakeratosis mucosa around the implant body, and radiographic examination showing marginal bone loss over three or more fixture threads mesially or distally. Healthy gingival tissues (approximately $1 \mathrm{~mm} \times 1 \mathrm{~mm} \times 1 \mathrm{~mm}$ ) were collected from the normal periodontium of 10 healthy subjects (five males and five females aged 20-60 years with an average age of 44.8 years) after teeth extraction for orthodontic or impacted reason under the following inclusion criteria: probing depth $<3 \mathrm{~mm}$, clinical attachment loss $<1 \mathrm{~mm}$ and without radiographic evidence of alveolar bone loss in the whole dentition. The samples from all subjects were acquired through periodontium biopsy. Exclusion criteria were as follows: individuals with known systemic risk factors such as diabetes or smoking, patients on medications, pregnant women and immunoincompetent subjects. Age and gender were matched in three groups. The purpose and procedures of the study were explained to the subjects, and informed consent was obtained from each individual. The protocol of this study was approved by the ethics committee of the West China Hospital of Stomatology, Sichuan University.

\section{Pre-treatment of samples}

The specimens were immediately washed with saline solution and stored in liquid nitrogen (YDS-3, Jinfeng Liquid Nitrogen Co. Ltd., Chengdu, China) and then transferred into a refrigerator at $-80{ }^{\circ} \mathrm{C}$ (Ultra-Low Temperature Fridge; NuAire Inc., Plymouth, USA).

Tissue masses $(50 \mathrm{mg}$ ) acquired from each specimen were cut into pieces and transferred into a $1.5 \mathrm{~mL}$ Eppendorf (EP) tube containing $1 \mathrm{~mL}$ Trizol. The homogenate was immediately crushed. The EP tube was placed on ice for a while and then centrifuged $\left(12000 \mathrm{r} \cdot \mathrm{min}^{-1}\right)$ at $4{ }^{\circ} \mathrm{C}$ (Megafuge 1.0R microthermal high-speed centrifuge; Heraeus, Hanau, Germany). The supernatant was shifted into an EP tube pretreated with di-ethylpyrocarbonate. Finally, the sample was placed at room temperature for $5 \mathrm{~min}$ to crack completely.

\section{RNA extraction}

After adding $0.2 \mathrm{~mL}$ chloroform into the pre-treated samples, they were placed in a spiral whirling device for $15 \mathrm{~s}$ and allowed to stand at room temperature for 2-3 min. Afterwards, the samples were centrifuged at $12000 \mathrm{r} \cdot \mathrm{min}^{-1}$ for $15 \mathrm{~min}$ at $4{ }^{\circ} \mathrm{C}$. The supernatant was transferred into an EP tube pre-treated with di-ethylpyrocarbonate. The EP tube was added with $0.5 \mathrm{~mL}$ isopropanol, turned upside down, and then placed on ice for $10 \mathrm{~min}$ of precipitation. The sample was centrifuged at $12000 \mathrm{r} \cdot \mathrm{min}^{-1}$ for $10 \mathrm{~min}$ at $4{ }^{\circ} \mathrm{C}$. A gelatinous RNA deposit was observed at the bottom of the tube; the supernatant was discarded. After adding $1 \mathrm{~mL}$ of $75 \%$ ethanol and mixing in a spiral whirling device, the sample was centrifuged again at $12000 \mathrm{r} \cdot \mathrm{min}^{-1}$ for $5 \mathrm{~min}$ at $4{ }^{\circ} \mathrm{C}$. The supernatant was then discarded. The liquid was completely absorbed after further instant centrifugation. Finally, the RNA was dried, uncovered, dissolved in $20 \mu \mathrm{L}$ di-ethylpyrocarbonate and then preserved at $-80{ }^{\circ} \mathrm{C}$.

\section{RNA quality testing}

The ratio of $\mathrm{OD}_{260} / \mathrm{OD}_{280}$ after diluting the RNA solution was measured, and electrophoresis with a $5 \mu \mathrm{L}$ sample in $1 \%$ agarose gel (electrophoresis apparatus; Bio-Rad Inc., Hercules, CA, USA) was performed to detect the purity of total RNA.

\section{Reverse transcription}

Using the mRNA in the total RNA as template, cDNA was obtained by reverse transcription with a random primer using a Revert Aid First Strand cDNA Synthesis Kit (MBI Inc., Davis, CA, USA). Total RNA $(5 \mu \mathrm{L})$ was premixed with $1 \mu \mathrm{L}$ of $0.2 \mu \mathrm{g} \cdot \mu \mathrm{L}^{-1}$ random hexamer primer and $6 \mu \mathrm{L}$ of nuclease-free deionized water. Instant centrifugation was then performed, followed by pre-treatment at $70{ }^{\circ} \mathrm{C}$ for $5 \mathrm{~min}$, and then ice cooling. Approximately $4 \mu \mathrm{L}$ of $5 \times$ reaction buffer, $1 \mu \mathrm{L}$ of $20 \mathrm{U} \cdot \mu \mathrm{L}^{-1}$ recombinant ribonuclease inhibitor, $2 \mu \mathrm{L}$ of $10 \mathrm{mmol} \cdot \mathrm{L}^{-1} \mathrm{dNTP}$ mix and $1 \mu \mathrm{L}$ of $200 \mathrm{U} \cdot \mu \mathrm{L}^{-1}$ RevertAid MMuLV reverse transcriptase were added into the mixture, followed by centrifugation. The reaction was performed at $20{ }^{\circ} \mathrm{C}$ for $10 \mathrm{~min}$, $42{ }^{\circ} \mathrm{C}$ for $60 \mathrm{~min}$, followed by $70{ }^{\circ} \mathrm{C}$ for $10 \mathrm{~min}$ in a PCR instrument (PerkinElmer Genetics, Bridgeville, PA, USA). Finally, the acquired cDNA solutions were preserved in a refrigerator at $-20{ }^{\circ} \mathrm{C}$.

\section{Design of primer}

According to the gene sequence of cFn in GenBank (Gene ID: 2335) and the primer designing rules, the upstream and downstream PCR primers for $\mathrm{cFn}$ were designed as $5^{\prime}$-CCA TCG CAA ACC GCT GCC AT-3' and 5'-AAC ACT TCT CAG CTA TGG GCT T-3', respectively. In this experiment, the gene of glyceraldehyde 3-phosphate dehydrogenase (GAPDH) was selected as reference. According to its sequence in GenBank (Gene ID: NM_002046), the sequences of the upstream and downstream PCR primers for GAPDH were 5' - AAG AAG GTG GTG AAG CAG GC-3' and 5' -TCC ACC ACC CTG TTG CTG TA-3', respectively.

\section{Processing real-time PCR}

We diluted the cDNA solution based on a specific gradient $\left(10^{0}, 10^{1}\right.$, $10^{2}, 10^{3}, 10^{4}$ and $10^{5}$ ) with EASY dilution. Each reaction contained $3 \mu \mathrm{L}$ of $\mathrm{Mg}^{2+}$ free $10 \times$ buffer, $3 \mu \mathrm{L}$ of $25 \mathrm{mmol} \cdot \mathrm{L}^{-1} \mathrm{MgCl}_{2}, 0.36 \mu \mathrm{L}$ of $25 \mathrm{mmol} \cdot \mathrm{L}^{-1} \mathrm{dNTP}, 1 \mu \mathrm{L}$ of $10 \mu \mathrm{mol} \cdot \mathrm{L}^{-1}$ upstream primer, $1 \mu \mathrm{L}$ of $10 \mu \mathrm{mol} \cdot \mathrm{L}^{-1}$ downstream primer, $1 \mu \mathrm{L}$ of $10 \mu \mathrm{mol} \cdot \mathrm{L}^{-1} 10000 \times \mathrm{SYBR}$ green I, $0.3 \mu \mathrm{L}$ of $5 \mathrm{U} \cdot \mu \mathrm{L}^{-1}$ Taq polymerase, $15.34 \mu \mathrm{L}$ of $\mathrm{ddH}_{2} \mathrm{O}$ and $5 \mu \mathrm{L}$ of cDNA template. Amplification was performed by 45 cycles of $94{ }^{\circ} \mathrm{C}$ for $20 \mathrm{~s}, 55{ }^{\circ} \mathrm{C}$ for $20 \mathrm{~s}, 72{ }^{\circ} \mathrm{C}$ for $30 \mathrm{~s}$ and $80{ }^{\circ} \mathrm{C}$ for $20 \mathrm{~s}$ in an FTC2000 fluorescent real-time PCR instrument (Funglyn Biotech Co., Scarborough, Canada). The target gene and reference gene were amplified. After amplification, the whole system was heated slowly to $95{ }^{\circ} \mathrm{C}$ (increasing by $1{ }^{\circ} \mathrm{C}$ every $5 \mathrm{~s}$ ) to obtain the melting curve.

\section{Statistical analysis}

Statistical calculations were made using a software package (SPSS 17.0; IBM Co., New York, NY, USA). The differences were considered significant when the probability value was less than 5\% $(P<0.05)$. SKEW and KURT tests were first used to test the data for normality. Levene test was then conducted to examine the homogeneity of variance for multiple samples.

Normally distributed data were expressed as means and standard deviations. For three-group comparisons, one-way analysis of variance was adopted first, aiming to examine whether the differences exist among these three groups, that is, whether the effect of random error (variation within groups, caused by age, gender, etc.) could be neglected comparing with the effect caused by grouping factor( peiodontitis, peri-implantitis, healthy). If the differences indeed exist among these groups, then Dunnett's $t$-test would be applied to 


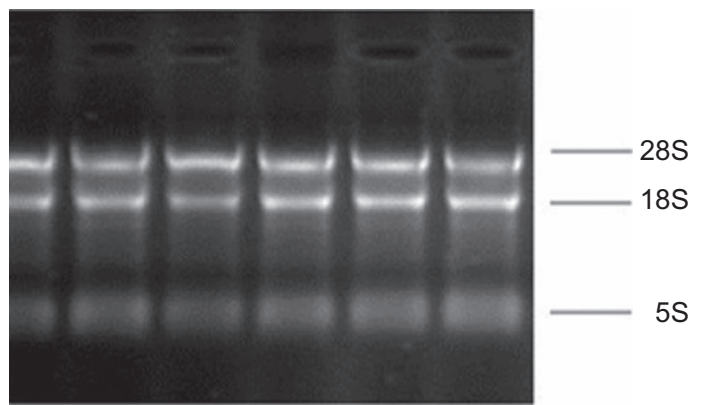

Figure 1 Partial electrophoresis pattern of total RNA for all the samples. Different lanes correspond to samples extracted from different subjects. The brightness of the three bands (28S rRNA, 18S rRNA and 5S rRNA) was degressive, and no obvious dispersive trace could be found. The ratio of brightness for 28S and $18 \mathrm{~S}$ was around 2:1, illustrating that the RNA is of high quality. rRNA, ribosomal RNA. evaluate the difference between any test group and the control group.

\section{RESULTS}

Evaluation of the purity and integrity of total RNA

The $\mathrm{OD}_{260} / \mathrm{OD}_{280}$ of all samples' RNA was between 1.8 and 2.0, indicating that the purity of total RNA was relatively high. The bands of 28S, $18 \mathrm{~S}$ and $5 \mathrm{~S}$ from the electrophoresis were distinct and showed no degraded bands (Figure 1).

\section{The melting curve}

As shown in Figure 2, the melting curve of the PCR products indicated that only one single temperature peak appeared for the cFn- and GAPDH-amplifying segments. This result indicates that the specificity

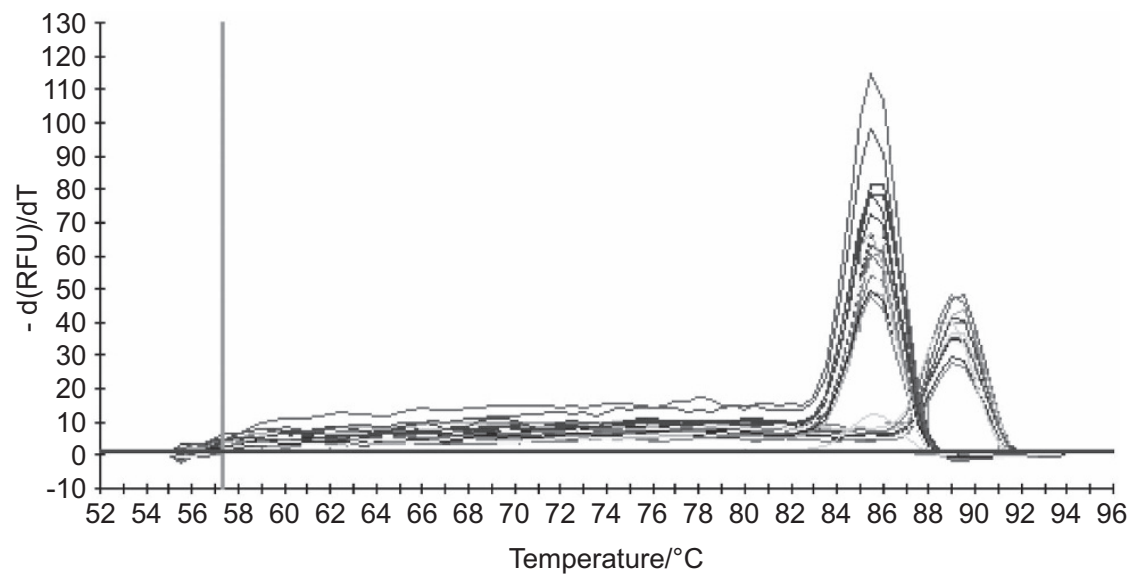

Figure 2 Melting curve of PCR products. The abscissa represents temperature, whereas the ordinate stands for change in fluorescent intensity. A single peak for GAPDH- (left) and cFn- (right) amplified products shows the high specificity of the primer. cFn, cellular fibronectin; GAPDH, glyceraldehyde 3-phosphate dehydrogenase; PCR, polymerase chain reaction.

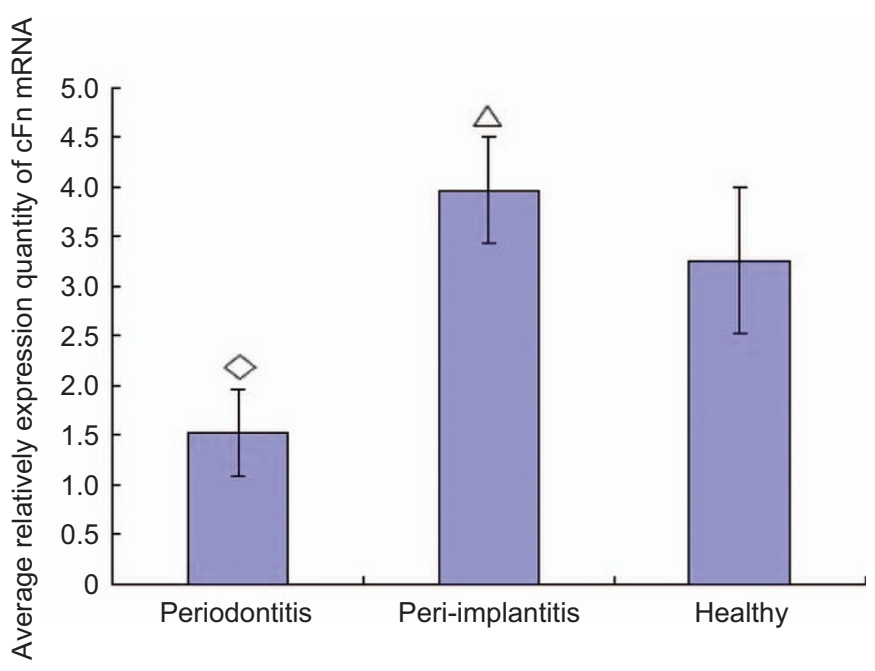

Figure 3 Comparison of average relative quantity for cFn mRNA among the periodontitis, peri-implantitis and healthy groups. Values and error bars of average relative expression quantity represent the means and s.d. of three groups $(n=10) .{ }^{\diamond} P<0.01$ versus healthy controls; ${ }^{\triangle} P<0.05$ versus healthy controls. cFn, cellular fibronectin; mRNA, messenger RNA. of both segments was very high and that no other pollution from the non-specific strips was observed.

mRNA expression of $\mathrm{cFn}$ in the periodontitis, peri-implantitis and healthy groups

The cFn mRNA could be detected in all the samples acquired from the periodontitis, peri-implantitis and healthy groups. The average relative expression quantities of cFn mRNA in the periodontitis, periimplantitis and healthy groups were $1.526 \pm 0.441,3.965 \pm 0.537$ and $3.253 \pm 0.736$, respectively. As shown in Figure 3, this result indicates that the transcription of $\mathrm{cFn}$ in the periodontitis group was lower than that in the healthy group $\left(t_{\mathrm{D}}=-6.613, P<0.01\right)$, while the mRNA expression of $\mathrm{cFn}$ in the peri-implantitis group was higher than that in the healthy group $\left(t_{\mathrm{D}}=2.732, P<0.05\right)$.

\section{DISCUSSION}

Fibronectin has two major forms: plasma fibronectin and cFn. Plasma fibronectin, the product of hepatocytes and endothelial cells, is soluble and exists in plasma and body fluids, where it stimulates blood clot formation $^{5}$ and wound healing. ${ }^{6} \mathrm{cFn}$ is secreted by a series of cells, mainly fibroblasts, in an insoluble form and is found in the extracellular matrix or on the surface of cells. ${ }^{7-9} \mathrm{cFn}$ is a major non-collagenous 
glycoprotein with multiple adhesive properties in periodontal tissues, functioning as a vital link between cells and their extracellular matrix. $^{10}$

The concentration of cFn in gingival crevicular fluid was found to be higher in healthy sites than in gingivitis sites. ${ }^{11}$ The degradation of $\mathrm{cFn}$ tends to be greater at diseased sites than at healthy or treated sites of periodontitis. ${ }^{12}$ Mintz and Fives-Taylor ${ }^{13}$ discovered that the level of cFn in individuals with adult periodontitis is significantly lower than that in individuals with healthy periodontal condition. Ma et al. ${ }^{14-15}$ reported that the quantity of periodontal $\mathrm{cFn}$ is higher in patients with peri-implantitis than in healthy individuals.

In connection with the decreasing cFn level in periodontitis, human neutrophil elastase has an important function. Neutrophil elastase is secreted by neutrophilic leukocytes, which are attracted to infected periodontal tissues by chemoattractants from bacteria, host cells or degraded tissue. ${ }^{16-17}$ Neutrophil elastase is the most important enzyme that degrades fibronectin to Fn fragments in vivo. ${ }^{18-19}$ The activity of neutrophils to release elastase is significantly increased in periodontitis patients than in healthy controls. ${ }^{20-22}$ An increase in neutrophil elastase activity increases fibronectin degradation fragments and decreases periodontal mechanical strength. ${ }^{23}$ In addition, clinical treatments such as scaling, root planning and curettage weaken elastase activity and restore cFn level. ${ }^{24}$

However, the situation differs in patients with peri-implantitis. In fibroblast cell culture, titanium (Ti) can significantly enhance the expression of $\mathrm{cFn} .{ }^{3}$ Ti surfaces have an affinity for fibronectin, which enables cFn to bind to the implant surface. ${ }^{25-26}$ Various studies have demonstrated that implant sites with peri-implantitis have higher elastase activity than healthy sites. ${ }^{27-28}$ However, the expression of cFn is still higher in patients with peri-implantitis than in individuals with healthy periodontal condition. Thus, the generation of cFn induced by $\mathrm{Ti}$ implants surpasses its degradation by elastase.

In this study, we compared the mRNA expression of cFn in periodontitis, peri-implantitis and healthy gingival tissues. Real-time PCR results displayed that the transcription of $\mathrm{CFn}$ in the peri-implantitis group was higher than that in the healthy group. By contrast, the mRNA expression of $\mathrm{cFn}$ in the periodontitis group was lower than that in the healthy group. This result suggests that in periodontitis, the decrease in cFn is not only due to the rising elastase level, but also to the declining mRNA quantity, which may lead to a more decisive effect. Thus, the inflammation process may affect the gene expression of periodontal cells, and cFn may act as a marker that indicates the impairment condition or therapy effect in periodontitis. However, in cases with peri-implantitis, the gene transcription intensifies regardless of the inflammation situation. We speculate that $\mathrm{Ti}$ implants stimulate $\mathrm{cFn}$ gene transcription and that this incitement offsets the effect of inflammation on periodontal cells. The elevated transcriptional level of $\mathrm{cFn}$ may be attributed to ability of Ti to enhance the fibroblast attachment for implants in vivo. The level of cFn is slightly related to the process of inflammation in peri-implantitis. Thus, cFn quantity may not serve as an index in this disease.

The real-time PCR technique utilized in this experiment was designed according to the reaction kinetics of PCR. With the fluorescent dye SYBR Green I, the standard curve of the $c F n$ and GAPDH genes could be drawn according to the dilution degree and their $C_{\mathrm{t}}$ value. As for the standard curve, the concentration of the target gene could be calculated if the $C_{\mathrm{t}}$ value was obtained. Then, the content of the $c F n$ gene was divided by that of the reference gene in the same sample. This way, the comparison for the expression level of all target genes would be on the same base, and the results would be credible and repeatable. The average relative expression quantities of mRNA in the results were acquired in this method.

\section{CONCLUSIONS}

The mRNA expression of cFn in the periodontitis group was lower than that in the healthy group. By contrast, the mRNA expression of cFn in the peri-implantitis group was higher than that in the healthy group. This change began during the transcriptional period. Although these two diseases are both inflammatory destructive processes in the periodontium, the pathomechanisms are somewhat diverse. cFn may be recognized as an indicator of periodontitis but not of peri-implantitis because Ti may affect the expression of $\mathrm{cFn}$ in the periodontium.

However, due to the small sample size and the different nature of the samples collected, bias may have been introduced. Further experiments are expected to support the conclusions above and to investigate the functions of other substance in these two diseases.

\section{ACKNOWLEDGEMENTS}

This work was supported by the National Natural Science Foundation (Project No. 81070868/H1409) and the State Key Laboratory of Oral Diseases, Sichuan University.

1 Talonpoika J, Heino J, Larjava $\mathrm{H}$ et al. Gingival crevicular fluid fibronectin degradation in periodontal health and disease. Scand J Dent Res 1989; 97(5): 415-421.

2 Bartold PM, Seymour GJ, Cullinan MP et al. Effect of increased community and professional awareness of plaque control on the management of inflammatory periodontal diseases. Int Dent J 1998; 48(3 Suppl 1): 282-289.

3 Chou L, Firth JD, Nathanso ND et al. Effects of titanium on transcriptional and posttranscriptional regulation of fibronectin in human fibroblasts. J Biomed Mater Res 1996; 31(2): 209-217.

4 Herrick S, Ashcroft G, Ireland G et al. Up-regulation of elastase in acute wounds of healthy aged humans and chronic venous leg ulcers are associated with matrix degradation. Lab Invest 1997; 77(3): 281-288.

5 Cho J, Mosher DF. Role of fibronectin assembly in platelet thrombus formation. J Thromb Haemost 2006; 4(7): 1461-1469.

6 Midwood KS, Mao Y, Hsia HC et al. Modulation of cell-fibronectin matrix interactions during tissue repair. J Investig Dermatol Symp Proc 2006; 11(1): 73-78.

7 Hynes RO. Fibronectins. Sci Am 1986; 254(6): 42-51.

8 Wierzbicka-Patynowski I, Schwarzbauer JE. The ins and outs or fibronectin matrix assembly. J Cell Sci 2003; 116(16): 3269-3276.

9 Mao Y, Schwarzbauer JE. Fibronectin fibrillogenesis, a cell mediated matrix assembly process. Matrix Biol 2005; 24(6): 389-399.

10 Henderson B, Nair S, Pallas J et al. Fibronectin: a multidomain host adhesion targeted by bacterial fibronectin-binding proteins. FEMS Microbiol Rev 2011; 35(1): 147-200.

11 Lopatin DE, Caffesse ER, Bye FL et al. Concentrations of fibronectin in the sera and crevicular fluid in various stages of periodontal disease. J Clin Periodontol 1989: 16(6): 359-364

12 Talonpoika J, Paunio K, Soderling E. Molecular forms and concentration of fibronectin and fibrin in human gingival crevicular fluid before and after periodontal treatment. Scand J Dent Res 1993; 101(6): 375-381.

13 Mintz KP, Fives-Taylor PM. Binding of the periodontal pathogen. Actinobacillus actinomycetemcomitans o extracellular matrix proteins. Oral Microbiol Immunol 1999; 14(7): 109-116.

14 Ma J, Sorsa T, Knnen M et al. Cellular fibronectin in failing dental implants. Int J Oral Maxillofac Implants 2002; 17(6): 363-368.

15 Ganor $\mathrm{Y}$, Besser M, Ben-Zakay N et al. Human T cells express a functional ionotropic glutamate receptor GluR3, and glutamate by itself triggers integrin-mediated adhesion to laminin and fibronectin and chemotactic migration. J Immunol 2003; 170(8): 4362-4372.

16 Uitto VJ, Overall CM, McCulloch C. Proteolytic host cell enzymes in gingival crevice fluid. Periodontology 2002; 3(31): 77-104.

17 Nussbaum G, Shapira L. How has neutrophil research improved our understanding of periodontal pathogenesis? J Clin Periodontol 2011; 38(Suppl 11): 49-59.

18 McDonald JA, Kelley DG, Broekelmann TJ. Role of fibronectin in collagen deposition: $\mathrm{Fab}^{\prime}$ to the gelatin-binding domain of fibronectin inhibits both fibronectin and collagen organization in fibroblast extracellular matrix. J Cell Biol 1982; 92(2): 485-492.

19 Ujiie Y, Oida S, Gomi K et al. Neutrophil elastase is involved in the initial destruction of human periodontal ligament. J Periodont Res 2007; 42(4): 325-330.

20 Ingman $\mathrm{T}$, Kononen $\mathrm{M}$, Konttinen $\mathrm{YT}$ et al. Collagenase, gelatinase and elastase activities in sulcular fluid of osseointegrated implants and natural teeth. J Clin Periodontol 1994; 21(4): 121-125.

21 Smith QT, Harriman L, Au GS et al. Neutrophil elastase in crevicular fluid: comparison of a middle-aged general population with healthy and periodontitis groups. J Clin Periodontol 1995; 22(12): 935-941. 
22 Figueredo CM, Areas A, Miranda LA et al. The short-team effectiveness of non-surgical treatment in reducing protease activity in gingival crevicular fluid from chronic periodontitis patients. J Clin Periodontol 2004; 31(8): 615-619.

23 Ujiie $\mathrm{Y}$, Shimada A, Komatsu $\mathrm{K}$ et al. Degradation of noncollagenous components by neutrophil elastase reduces the mechanical strength of rat periodontal ligament. J Periodont Res 2008; 43(1): 22-31.

24 Ingman T, Kononen M, Konttinen YT et al. Collagenase, gelatinase and elastase activities in sulcular fluid of osseointegrated implants and natural teeth. J Clin Periodontol 1994; 21(4): 301-307.

25 Elias CN, Gravina PA, Silva Filho CE et al. Preparation of bioactive titanium surfaces via fluorideand fibronectin retention. Int J Biomater 2012; 2012: 290179.

26 McDonald JA, Kelley DG, Broekelmann TJ. Role of fibronectin in collagen deposition: $\mathrm{Fab}^{\prime}$ to the gelatin-binding domain of fibronectin inhibits both fibronectin and collagen organization in fibroblast extracellular matrix. J Cell Biol 1982; 92(2): 485-492.

27 Salvi GE, Lang NP. Diagnostic parameters for monitoring peri-implant conditions. Int J Oral Maxilofac Implants 2004; 19(Suppl): 116-127.

28 Hultin M, Gustafsson A, Hallström H et al. Microbiological findings and host response in patients with peri-implantitis. Clin Oral Implants Res 2002; 13(4): 349-358.

(c) This work is licensed under a Creative Commons SOMERIGHIS BESERVED Attribution-NonCommercial-NoDerivative Works 3.0 Unported License. To view a copy of this license, visit http:// creativecommons.org/licenses/by-nc-nd/3.0 